\title{
COMPARATIVE ANALYSIS OF NATIONAL APPROACHES TO MILITARY CAPABILITY PLANNING
}

\author{
Zdenek PETRAS \\ Centre for Security and Military Strategy Studies, University of Defence, Brno, \\ The Czech Republic \\ zdenek.petras@unob.cz
}

\begin{abstract}
National defence planning processes are often compared with the NATO Defence Planning Process (NDPP). Taking into account that NDPP needs commonly agreed criteria to evaluate military capabilities of the different nations, and given the significant effort invested in performance measurement by several nations, it would be beneficial to examine how respective nations are currently assessing their performance within the capability-based planning process, with a view to establishing potential common measures that would benefit individual nations while addressing the needs of NATO at the same time. The principles which the NDPP is based on are referred to in some of national defence strategic documents, although there is no explicitly statement that the national defence planning process should be tailored in the same way as it is the case of the NDPP. In order to find an answer to the above mentioned issue and identify common practices and lessons to support capability planning within nations and NATO an analysis was carried out with the objective of identifying to which extent national planning processes of respective nations correlate with principles of NDPP as well as with principles of the EU capability development.
\end{abstract}

\section{Keywords: capability planning, shortfalls, assessment, prioritisation}

\section{Introduction}

The defence planning process, as set up within some of NATO nations is often matching against the NATO Defence Planning Process (NDPP) even if there is no explicitly stated that the national defence planning processes should be tailored in the same way as it is the case of the NDPP. It is absolutely unquestionable that one of main objectives of all NATO nations and their national defence planning processes must be to fulfil the Alliance ambition requirements. However it is questionable whether this fact calls for in-depth analysing NATO approaches to the defence planning with a view to implement them into national defence environment. In order to find an answer to the above mentioned issue, it was carried out an analysis whose objective was specifically aimed at:

-identifying to which extent national planning processes of respective nations correlate with principles of NDPP as well as with principles of the EU capability development;

- identifying positive findings and best practices from national capability planning processes to be exploited when conceiving a specific national approach to capability planning.

\section{Setting Up of Analysis Framework}

The basic prerequisite for starting out the analysis was to construct a suitable structure of nations to be submitted to the comparative research. Selecting of nations was thereupon based on criteria a follows:

- only European nations of NATO and EU were taken as the subject of the research;

- research included NATO nations and EU member states as well members of both NATO and EU; 
- objective was to scrutinise small and medium-sized nations as well as nations which are considered as large from geographical and population point of view;

- research included both longstanding members of NATO/EU and nations joining NATO or EU recently, i.e. after 1999 as for the NATO and the EU after 2004;

- research was made only on nations for which there were available national conceptual documents such as defence white books, national defence strategies, doctrines etc., dealing with defence planning and capability development.

Finally, 12 nations met the eligibility criteria: Belgium, the Netherlands, France, Germany, Denmark, Italy, Estonia, Poland, the United Kingdom, Sweden, Finland and Norway. Regarding to the expected outcomes, the research was based on the literature review arisen from conceptual a strategic documents dealing with defence planning and capability development within the context of nation defence and security policies (see the table 1).

Even if results of the research stem from the group of only 12 nations (which can be hardly considered as a statistically significant number, taken into account the total of 22 nations being members of both EU and NATO), an overall structure and characteristics of scrutinised nations allow to draw up a few important conclusions.

Table 1-List of publications used for the literature review (Source: Author)

\begin{tabular}{|l|l|}
\hline \multicolumn{1}{|c|}{ Nation } & \multicolumn{1}{c|}{ Title } \\
\hline Belgium & The Modernisation Plan 2000 - 2015 of the Belgian Armed Forces \\
\hline Netherlands & Netherlands Defence Doctrine \\
\hline France & Défense et sécurité nationale 2013: livre blanc \\
\hline Germany & White Paper 2006 on German Security Policy and the Future of the Bundeswehr \\
\hline Denmark & Danish Defence Agreement 2010 - 2014 \\
\hline \multirow{2}{*}{ Italy } & Il libro bianco per la sicurezza internazionale e la difesa \\
\cline { 2 - 3 } & La Dottrina Militare Italiana \\
\hline \multirow{2}{*}{ Estonia } & National Security Concept of the Republic of Estonia - 2004 \\
\cline { 2 - 3 } Poland & Estonian Long Term Defence Development Plan 2009-2018 \\
\hline \multirow{3}{*}{ UK } & $\begin{array}{l}\text { Defence Strategy of the Republic of Poland: Sector Strategy of the National } \\
\text { Security Strategy of the Republic of Poland }\end{array}$ \\
\cline { 2 - 3 } Sweden & Biata ksiega - White paper \\
\hline & A strong Britain in an age of uncertainty: the national security strategy \\
\cline { 2 - 2 } & Delivering Security in a Changing World: Future Capabilities \\
\cline { 2 - 2 } & $\begin{array}{l}\text { Sweden's Security in the 21st Century. } \\
\text { Swedish Government Bill 2004 -2005: Our Future Defence - The Focus of }\end{array}$ \\
\hline \multirow{2}{*}{ Finland } & Finnish Security and Defence Policy 2012: Government Report \\
\cline { 2 - 2 } & Securely into the Future: Ministry of Defence Strategy 2025 \\
\hline \multirow{2}{*}{ Norway } & Norwegian Defence 2008 \\
\cline { 2 - 2 } & Norwegian Defence 2013: Facts and Figures \\
\hline
\end{tabular}

\section{Research Method Setting Up}

As a methodological principle for conducting the research, a set of comparative determinants was established to compare respective national defence planning approaches and to assess the extent with which selected nations give priority to their national concerns against NATO or EU strategic objectives. These determinants came out as a result from the 
combination of the Strategic Map method and operational art elements - Means, Ways and Ends (see the figure 1). The combination of the Strategic Map and operational art is described in the Joint Operation Planning [1] which specifies procedures through planning, preparing and executing military operations led by the US Army. However this method is frequently applied by many NATO and EU nations not only for operations planning purposes.

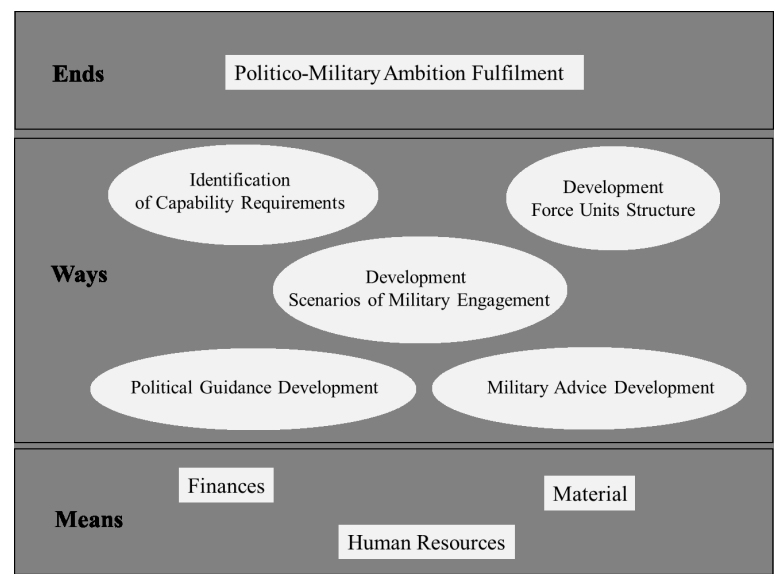

Figure 1 -Combination of Strategic Map and Operational Art Elements (Source: Author)

Subsequently, the element Ways was modified accordingly in order to specifically reflect a generic design of defence planning processes as applied within scrutinized nations.

The modification of the element Ways stems from a generic framework of defence planning process that is basically launched by a political guidance reflecting quite number of political, military, economic, legal, civil and technological factors having direct or indirect impact on global or local security situation.

Table 2 -Overview of determinates and their characteristics (Source: Author)

\begin{tabular}{|l|l|}
\hline \multicolumn{1}{|c|}{ Determinant } & \multicolumn{1}{|c|}{ Characteristics } \\
\hline Politico--strategic & $\begin{array}{l}\text { Prioritization of measures to eliminate security threats } \\
\text { stemming from the analysis of global and local security } \\
\text { environment }\end{array}$ \\
\hline Military strategic & $\begin{array}{l}\text { Role of armed forces within national and international } \\
\text { context }\end{array}$ \\
\hline Operational & $\begin{array}{l}\text { Delimitation of scenarios for operational engagement of } \\
\text { armed forces }\end{array}$ \\
\hline $\begin{array}{l}\text { Identification Capability } \\
\text { Requirements }\end{array}$ & $\begin{array}{l}\text { Delimitation of capability requirements needed for } \\
\text { accomplishing expected ambitions }\end{array}$ \\
\hline Force Units Structure & $\begin{array}{l}\text { Development of force units structure with respective } \\
\text { components as a tool for accomplishment of expected } \\
\text { ambitions }\end{array}$ \\
\hline
\end{tabular}


4. Outcomes of Determinants Application The comparative determinants applied on scrutinised nations enabled to disclose their priorities in term of national concerns against ambitions as specified in the NATO or EU defence and security policies. The leading factor of the research leant on the premise according to which the relation between national strategic concerns and NATO's collective defence principles or EU's common security and defence policy was playing a crucial role while setting orientation in national capability development process. Outcomes resulting from the research are summarised in the table 3 .

Table 3 -Outcomes from application of determinants to individual nations (Source: Author)

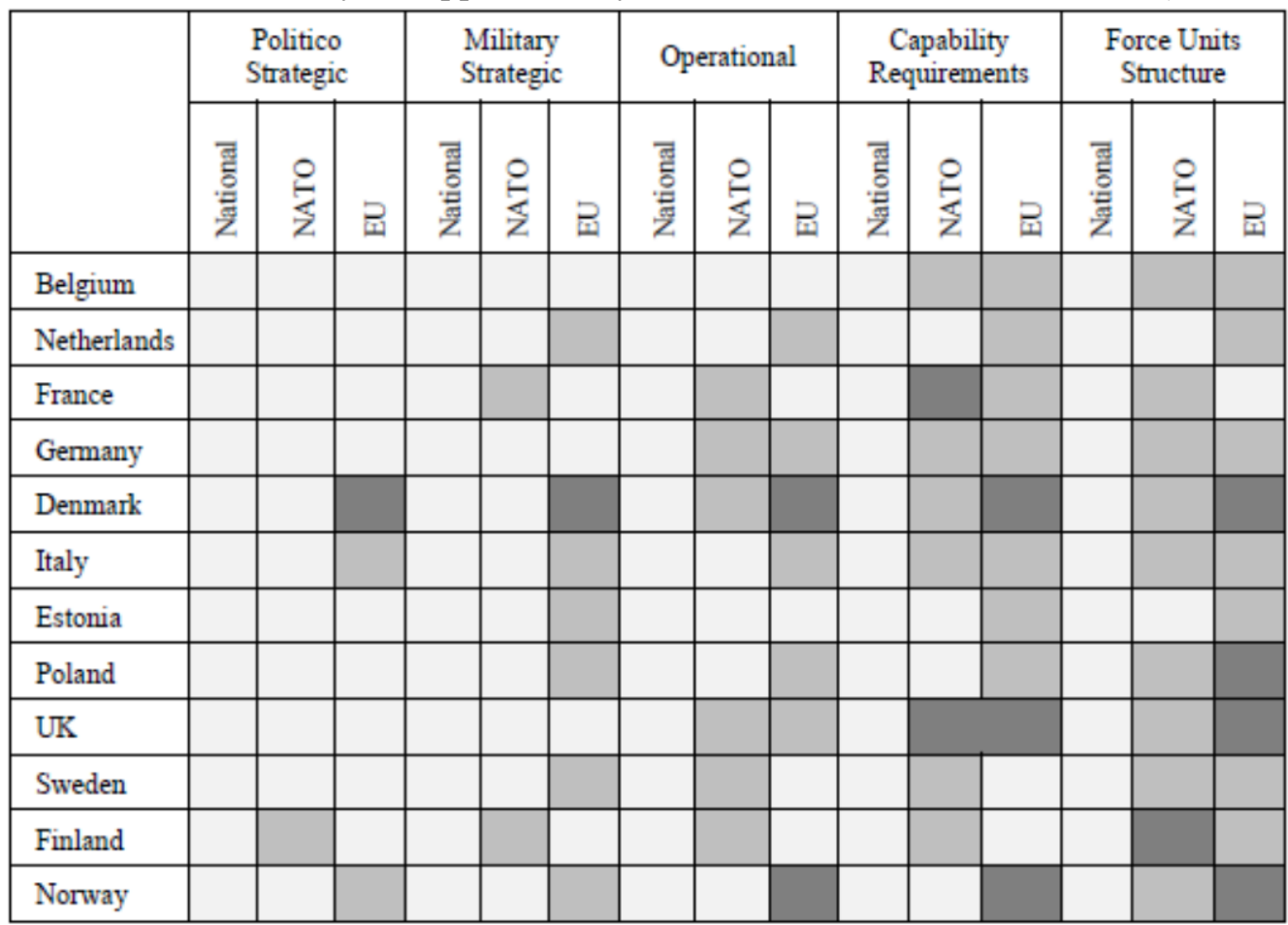

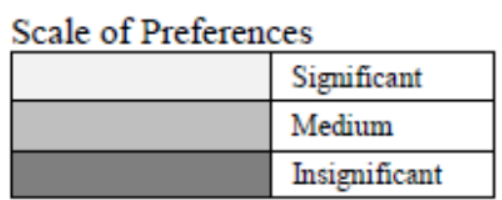

\subsection{Politico-Strategic and Military Strategic Determinants}

Results from application of both politicostrategic and military-strategic determinants express that all 12 nations accentuate a need for a strong coexistence of national interests with NATO/EU ambitions, when conceiving their national security and defence policies and accompanying capability development plans. Nevertheless, the extent of preferences, with which nations reflect the NATO or EU planning principles, distinctively differentiate on nation to nation basis. For almost all nations, with slight exception of France, it is typical that principles as applied through the NATO defence planning are far more traceable than it is the case of EU planning principles. The only distinct exception is Denmark which is not participating in EU's defence and security policy.

Results of research showing which one of NATO or EU approach to defence planning is influencing individual nations are summarised in the table 4. 
Table 4 - Impact of NATO/EU approaches on national defence planning processes (Source: Author)

\begin{tabular}{|l|c|c|}
\hline & NATO & EU \\
\hline Belgium & $\mathrm{X}$ & $\mathrm{X}$ \\
\hline Netherlands & $\mathrm{X}$ & \\
\hline France & & $\mathrm{X}$ \\
\hline Germany & $\mathrm{X}$ & \\
\hline Denmark & $\mathrm{X}$ & \\
\hline Italy & $\mathrm{X}$ & \\
\hline Estonia & $\mathrm{X}$ & \\
\hline Poland & $\mathrm{X}$ & \\
\hline United Kingdom & & \\
\hline Sweden & & $\mathrm{X}$ \\
\hline Finland & & $\mathrm{X}$ \\
\hline Norway & $\mathrm{X}$ & \\
\hline
\end{tabular}

\subsection{Operational Determinant, Capability Requirements and Force Unit Structure}

However, for detailed depicting how individual nations are shaping their national defence planning processes, determinants Operational Determinants, Capability Requirements and Force Units Structure are determining. From national perspective, identification of capability requirements reflects a resultant of a few separate subprocesses which have a crucial importance for shaping further development of national armed forces and their potential to achieve expected ambitions. These sub-processes are:

1. identification of capability requirements as a result of analyses of short and medium-term perspective security threats,

2. identification of future trends in developing capability needs reflecting long-term perspective of security challenges,

3. analysis of lessons learned from planning, preparing and performing military operations,
4. adaptability of national defence technological and industrial base to provide with those weapon systems and technologies being able to fulfil respective capability needs.

For establishing the specific sub-processes, the structure of the EU's Capability Development Plan (CDP) [2] was taken as a methodological base. $C D P$ provides an analysis of the security environment in the world within medium to long term prospective and identifies capabilities needed to eliminate arising security challenges. The document proposes a common approach of EU member states to capability development based on four subprocesses. In a perfect case, all these subprocesses are supposed to be in close crossconnection. The approach as described in the $C D P$ was applied on all scrutinised nations. The result of this application illustrated that not all of scrutinised nations proceed to the cross-connection in the same way. Outcomes from the analysis of national positions to respective subprocesses are shown in the table 5. 
Table 5 - Overview of national positions to sub-processes having impact on capability development (Source: Author)

\begin{tabular}{|c|c|c|c|c|}
\hline Sub-process & Sub 1 & Sub 2 & Sub 3 & Sub 4 \\
\hline Nation & Sub I & Sub 2 & Sub 3 & Sub 4 \\
\hline Belgium & $X$ & $X$ & & \\
\hline Netherlands & $\mathrm{X}$ & $X$ & $\mathrm{X}$ & \\
\hline France & $\mathrm{X}$ & $\mathrm{X}$ & $\mathrm{X}$ & $\mathrm{X}$ \\
\hline Germany & $\mathrm{X}$ & $\mathrm{X}$ & & $\mathrm{X}$ \\
\hline Denmark $\left.^{*}\right)$ & $X$ & $X$ & & \\
\hline Italy & $\mathrm{X}$ & $\mathrm{X}$ & & $\mathrm{X}$ \\
\hline Estonia & $\mathrm{X}$ & $\mathrm{X}$ & & \\
\hline Poland & $\mathrm{X}$ & $\mathrm{X}$ & & \\
\hline United Kingdom & $\mathrm{X}$ & $\mathrm{X}$ & $X$ & $\mathrm{X}$ \\
\hline Sweden & $\mathrm{X}$ & $\mathrm{X}$ & & $X$ \\
\hline Finland & $\mathrm{X}$ & $\mathrm{X}$ & & $X$ \\
\hline Norway & $X$ & $X$ & $X$ & \\
\hline
\end{tabular}

Notes:

Sub-process 1: Defining capability requirements in short-to-medium term perspective

Sub-process 2: Analysed lessons learned from military operations

Sub-process 3: Defining capability requirements in long term perspective

Sub-process 4: Adaptability of national defence technological and industrial base to meet capability requirements

${ }^{*}$ Denmark is not participating in EU's Common Security and Defence Policy structures.

From outcomes, as presented in the table 5, it is evident that all nations carry out identification of capability requirements in short-to-medium term perspective in combination with analysis of lessons learned from military operations. Nations, such as the Netherlands, Germany, Italy, Sweden, Finland and Norway, use to proceed also the identification of capability requirements in long term perspective and provide assessing to which extent their national defence technological and industrial base is able to reflect newly arisen capability requirements. For all scrutinised nations it is quite symptomatic that their processes of identification of capability requirements tend to be broadly applied across their national military force structures. [3]

In fact, only two nations, France and the United Kingdom, have set up a really functional cross-connection between all defined sub-processes. In other terms, this finding significantly stress the fact that only France and the UK have clearly shaped priorities in the area of national security and defence policy.

Taking into consideration all results, which stems from application of Operational Determinant, Identification of Capability Requirements and Force Units Structure, the three principal approaches to defence planning can be derived:

1. planning exclusively based on principles reflecting above all national defence and security policy (UK),

2. planning which is mainly focused on providing a collective defence within the Euro-Atlantic area in combination with national security and defence concerns (the Netherlands, Germany, Italy, Norway, Estonia, Poland),

3. planning focused on covering national security concerns in combination with ambitions stemming from EU's common 
defence and security policy (France, Sweden and Finland).

\section{Synthesis of Analysis Outcomes}

The synthesis of findings coming from the research of national approaches to the capability planning can be summarised as follows:

1. there is no national capability planning process which could be strictly considered as identical with NATO or EU planning processes,

2. regarding a complexity of national concerns and interests in the area of foreign and security policy, it is not all conceivable to create a standardised planning mechanism which might be accepted and implemented by all nations. This finding is applicable for both NATO nations and EU member states.

Outcomes from the comparative analysis point out that the principles of defence planning, as used within the NATO planning structures, influence the national approaches far more than the EU principles. Despite of lack of a common approach to capability planning, it is however possible to trace up a clear coherence between principles as applied within NATO, EU and national planning processes. This coherence consists in a need for harmonising and synchronising national planning processes with NATO/EU ones as well as for standardising elaboration of national inputs to NATO or EU planning process. [4]

The point is to elaborate accordingly national chapters to the NATO's Defence Planning Capability Survey (DPCS) in which nations periodically submit their national contributions to the NATO. One part of the DPCS is dedicated to summary of national contributions to the EU. That means that the $D P C S$ is a unifying element for summarising national contributions for both NATO and EU planning purposes. Therefore the key issue for NATO nations and EU member states is to submit only those national contributions which respect standard format and required parameters related to capabilities of their armed forces.

\section{Conclusions}

The analysis of national defence planning processes came out to conclusion that nations are using specifically tailored national approaches to capability planning. Diversity and fragmentation of national approaches to capability planning is due to different strategic concerns stemming from national security and defence policies which may not be necessarily consistent with NATO collective defence ambition or EU common security and defence policy. Results of the analysis illustrate that no nation have implemented planning procedures in the form of an integral process as used through NATO or EU. Even though any nation does not use NATO nor EU planning practice as a whole, principles as applied through NATO are commonly influencing national approaches far more than it is the case of EU planning principles.

With regard to national specificities as for politico-military ambitions, nations are also using approaches specifically tailored for conceiving military force structures, envisaged operational engagements of force units and capabilities which are identified as indispensable for achieving expected military and political end states. In certain cases, nations are using some of fragments from the NATO or EU capability planning processes, but appropriately modified to national purposes. For individual national approaches to defence planning, it is emblematic a close interconnection between identification of capability requirements and existing military force structure. At the national level of planning, it is typical that identified capability requirements are affiliated in advance to relevant force units. Especially while assigning priorities in capability development, nations usually tend to pre-identified force units which are supposed to get relevant capabilities.

However a common factor correlating approaches of nations, on the one side, and 
NATO and EU, on the other side, is a form under which individual nations are to send their national contributions to the NATO or to the EU. These national contributions containing respective capabilities are a key input for fulfilling expected ambitions of both NATO and EU.

As a general rule, national contributions should accordingly reflect capability taxonomy, which has been agreed to be commonly used by both NATO and EU. In October 2011, NATO issued a new document titled Bi-SC Agreed Capability Codes and Capability Statements [5] which provides a common language for capabilities that links defence planning with operations planning, and defines the capabilities requirements used in DPCS. This document was furthermore followed by another Alliance document, titled Bi-SC Capability Hierarchy [6], whose aim was to introduce a single terminology and hierarchical structure of Main Capability Areas.

A reflexion of NATO/EU capability requirements into national contributions is so a critical issue for an effective cooperation between both national and NATO/EU sides. This is also a reason for which Alliance and Union planning structures are permanently seeking to harmonise and synchronise national planning processes with NATO/EU ones. Thus, regardless the diversity of national approaches to capability planning, the final conclusion, which is likewise applicable into the Czech Ministry of Defence, is as follows:

Instead of an in-depth analysing of NDPP, national planners had better concentrate, in their efforts for optimising planning procedures, on setting up a national planning process to be able:

- to generate contributions to NATO and EU which strictly meet identified capability requirements;

- to put national contributions in due form by using agreed NATO/EU capability taxonomy and terminology with a view to provide smooth transfer of declared national capabilities into NATO or EU capability planning procedures.

\section{References}

[1] JOINT CHIEFS OF STAFF (ed.). Joint Publication 5-0: Joint Operation Planning. Washington, D.C.: Joint Chiefs of Staff, 2011, 1 v. (loose-leaf). Chapter III. Available at: http://www.dtic.mil/doctrine/new_pubs/jp5_0.pdf

[2] EUROPEAN DEFENCE AGENCY (ed.). Future Trends from the Capability Development Plan. European Defence Agency. Brussels, Belgium, 2008. Available also at: http://www.eda.europa.eu/docs/documents/Brochure_CDP.pdf

[3] NATO STO (ed.). RTO-MP-SAS-081 - Analytical Support to Defence Transformation: Analytic Implications of the NATO Defence Planning Process. Paris, France: CSO, 2010, p. 9 - 18. ISBN 978-92-837-0116-3. Available also at: https://www.cso.nato.int/pubs/rdp.asp?RDP=RTO-MP-SAS-081

[4] NATO STO (ed.). Cost Efficiency Implications of International Cooperation: Final Report of Task Group SAS-090. Neuilly-sur-Seine, Francie: NATO Science and Technology Organization, 2015, p. E-1. ISBN 978-92-837-0219-1. Available also at: https://www.cso.nato.int/Pubs/rdp.asp?RDP=STO-TR-SAS-090

[5] SHAPE/ACT (ed.). BI-SC Agreed Capability Codes and Capability Statements. SHAPE/CPPCAMFCR/JM/281143. Mons, Belgium, 2011.

[6] SHAPE/ACT (ed.). Bi-SC Capability Hierarchy. SH/PLANS/JCAP/FCP/15-310118. Mons, Belgium, 2015. 